Winder, F. G. \& Denneny, J. M. (1956). J. gen. Microbiol. 15, 1-18

\title{
Phosphorus Metabolism of Mycobacteria: Determination of Phosphorus Compounds in some Mycobacteria
}

\author{
BY F. G. WINDER AND JOAN M. DENNENY \\ Laboratories of the Medical Research Council of Ireland, Trinity College, Dublin
}

SUMMARY: A procedure is described for the determination of phospholipid, 'phosphoprotein', 'acid-soluble' phosphate, pentosenucleic acid (DNA), deoxypentosenucleic acid (DNA), and 'insoluble' polyphosphate in samples of mycobacteria of about $30 \mathrm{mg}$. dry weight.

The content of each of these fractions in a number of cultures of Mycobacterium smegmatis, $M$. phlei and $M$. tuberculosis was determined. Considerable variation in some of the fractions was found in different cultures of the one organism, especially in the case of $M$. smegmatis. The effect of the age of a culture on its content of each fraction was studied for $M$. smegmatis. Studies were made on the changes in the phosphate fractions during the first few hours after the introduction of a heavy inoculum into a fresh medium.

In the course of an investigation into the mode of action of some anti-tuberculosis phenazine pigments synthesized in these laboratories, we wished to study the effect of these pigments on the phosphorus metabolism of mycobacteria. The publications on this subject were few, and consisted of work on mycobacterial nucleic acids only (e.g. Chargaff \& Saidel, 1949; Marshak \& Vogel, 1951), and studies had first to be made on the adaptation of conventional techniques to the determination of the phosphorus compounds in these organisms. Since this work was started a number of papers have been published on other aspects of this subject: Ruska, Bringmann, Neckel \& Schuster (1952) have shown the presence of 'metaphosphate' in Mycobacterium avium; Sternberg \& Podoski (1953) have studied the turnover of some phosphorus-containing fractions of M. phlei; Meissner \& Kropp (1953) and Meissner \& Diller (1953) have studied the absorption of labelled phosphate by $\boldsymbol{M}$. tuberculosis; Mitchell \& Moyle (1954) give values for phosphorus-containing fractions of $M$. phlei. None of these papers, however, describes a critical study of methods for determining the components of the 'acid-insoluble' fraction of these bacteria.

Determinations were made of the phosphorus-containing fractions of several strains of mycobacteria. Some of the results for normally growing bacteria are given in this paper, and it is intended subsequently to publish studies on the effects of antibacterial agents on their phosphorus metabolism.

\section{METHODS}

Organisms used. The strains of Mycobacterium smegmatis and M. phlei have been maintained in these laboratories for a number of years.

Mycobacterium tuberculosis H37 Rv, H37Ra, R1Ra and Ravenel Rv were obtained from W. Steenken, Jun., Trudeau Laboratory. M. tuberculosis 
H37 RvN was a strain resistant to $100 \mu \mathrm{g}$. isoniazid $/ \mathrm{ml}$. Its origin and characteristics are described elsewhere (Barry, Conalty, Denneny, Gaffney \& Winder, 1955).

Culture and harvesting. The basic medium used was a Proskauer \& Beck medium prepared as recommended by the American Trudeau Society (1950). This medium will be referred to as $\mathbf{P} \& \mathbf{B}$. The saprophytic mycobacteria were maintained on a modification of $\mathrm{P} \& \mathrm{~B}$ which contained 6-10 $\mu \mathrm{g}$. ferric chloride (hydrated)/ml. In growing cultures for the experiments a small quantity of surface growth was lightly ground, suspended in $\mathbf{P} \& \mathbf{B}$, and a quantity of this inoculum containing about $0.2 \mathrm{mg}$. was pipetted into $80 \mathrm{ml}$. of the modified P \& B in $250 \mathrm{ml}$. conical flasks. The flasks were incubated at $37^{\circ}$. Mycobacterium tuberculosis was kept on Löwenstein-Jensen medium (containing $100 \mu \mathrm{g}$. isoniazid $/ \mathrm{ml}$. in the case of $\mathrm{H37} \mathrm{RvN}$ ). Material from 2- to 3-week-old cultures was ground and inoculated, as above, into $80 \mathrm{ml}$. of $\mathrm{P} \& \mathrm{~B}$ in $250 \mathrm{ml}$. conical flasks, which were then capped and incubated at $37^{\circ}$. When serum is mentioned as an addition to the medium, $5 \%$ human serum was used.

Harvesting was carried out when the culture had reached the desired stage of growth. When material was required for the short-term growth experiments, described below, harvesting was done when there was a uniform and fairly thick pellicle over the surface of the medium, just before growth had started to slow down (e.g. 3-4 days with Mycobacterium smegmatis). The rate of growth, however, was subject to considerable variation and no really adequate criterion of physiological age was available. The weight of organism per unit volume of medium was variable at any stage of growth. The appearance of the pellicle on the surface gave perhaps the best idea of the stage of growth that had been reached. As a consequence of this uncertainty, in studies on the effect of age on the composition of an organism, material from the same culture had to be used throughout.

Cultures to be harvested were transferred to a Büchner funnel, and washed with distilled water. They were then suspended in distilled water by grinding for a short period in a slowly rotating Pyrex ball-mill, containing agate balls. For analysis samples containing about $\mathbf{3 0} \mathrm{mg}$. dry weight were pipetted into $5 \times \frac{5}{8}$ in. Pyrex test tubes, in which all subsequent operations were performed. One set of samples was taken for dry weight, total nitrogen and total phosphorus determinations, and another set for fractionation.

When dealing with virulent Mycobacterium tuberculosis handling was carried out inside a cabinet until the stage of extraction with ethanol was reached (Fig. 1). The organisms were killed by suspending in acetone for $24 \mathrm{hr}$, followed by $24 \mathrm{hr}$. in $5 \%$ trichloroacetic acid (TCA), so that after this period the cold TCA extracts were innocuous.

Short-term growth experiments. Cultures which had reached a suitable stage of growth were transferred to a Büchner funnel, washed and suspended as above. The suspension was diluted to a constant turbidity (to give about $6 \mathrm{mg}$. bacterial dry weight $/ \mathrm{ml}$.). The bacteria showed no appreciable loss of acidfastness during this treatment. Forty $\mathrm{ml}$. of this suspension and $2 \mathrm{ml} . \mathbf{0 . 5} \%$ Tween 80 were added to $20 \mathrm{ml}$. medium contained in a $150 \mathrm{ml}$. conical flask. 


\section{Phosphorus compounds of mycobacteria}

The medium used had the same constituents as P \& B at three times the concentration, except that equimolar sodium citrate was substituted for magnesium citrate to avoid precipitation of phosphate. The flask was plugged with cotton wool, and shaken (at about 90 cycles/min.) in a water bath at $37^{\circ}$. Samples (5 or $10 \mathrm{ml}$.) were withdrawn as required.

Treatment of samples. The samples were chilled in ice, and centrifuged in the cold. The supernatant fluid was drawn off by a fine Pasteur pipette. The organisms were washed three times by stirring up in ice-cold distilled water, using fine glass rods, the tubes were centrifuged in the cold, and the supernatant fluid drawn off. The whole procedure was carried through rapidly.

\section{Determination of dry weight, total nitrogen and total phosphorus}

Where the dry weight was to be determined the samples were pipetted into weighed tubes. After the washing, the tubes were placed in an oven at $80^{\circ}$ overnight, allowed to cool in a desiccator and weighed. $1 \mathrm{ml}$. incinerating mixture ( $1: 1, \mathrm{v} / \mathrm{v}$, concentrated sulphuric acid and a strong solution of acid potassium sulphate containing $\mathbf{0 . 2} \%$ sodium selenate) and a glass bead were added. Incineration was carried out on a sand-bath according to the method of Hawes \& Skavinski (1942). The tubes were then cooled, $4 \mathrm{ml}$. distilled water added and the tubes placed in a boiling water bath for about $7 \mathrm{~min}$. They were then cooled, and the contents suitably diluted. Samples were taken for the determination of ammonia by microdiffusion (Conway, 1950), and for the determination of phosphate.

Extraction of phosphorus compounds. The bacterial mass was broken up with a glass rod. About $5 \mathrm{ml}$. acetone was added and the tube contents stirred well. The tubes were stored in the refrigerator overnight, or longer if necessary. The procedure to be described later (Fig. 1) was carried out on the samples. After each centrifuging the supernatant was pipetted off with a fine Pasteur pipette. The next extracting liquid was then added, and the same glass rods were replaced and used to suspend the bacterial residue in the liquid. The stirring was repeated several times during the longer extractions. The cold extractions were done in an ice-water mixture.

Total phosphorus in samples and residues. Ashing and subsequent inorganic phosphate determination were carried out as recommended by LePage (1949), but considerably longer incineration times were necessary for phospholipid and 'phosphoprotein'.

Acid-labile phosphate. In estimating acid-labile phosphate, $7 \mathrm{~min}$. hydrolysis at $100^{\circ}$ with $\mathrm{N}-\mathrm{HCl}$ was used. It was found that the $7 \mathrm{~min}$. hydrolysis was sufficient for the complete hydrolysis of the polyphosphate present in mycobacteria, though longer hydrolysis times have been adopted (Ebel, 1952). When nucleic acid was present in an extract, allowance had to be made for its hydrolysis. It was found that $23 \%$ of PNA phosphorus and $14 \%$ of DNA phosphorus were liberated by the $7 \mathrm{~min}$. hydrolysis.

Inorganic orthophosphate. The Fiske \& SubbaRow method (LePage, 1949) was employed. This method does not give completely reliable results in the 
presence of acid-labile phosphate compounds. Such compounds were present along with orthophosphate in the acid-soluble fraction. But comparison of results from this method with results obtained by the method of Berenblum \& Chain (1938) showed that the inaccuracy involved was small. No problem of a magnitude similar to that met by Bajaj \& Krishnan (1953) was encountered.

Ultraviolet absorption. Measurements were carried out using a Beckman model DU spectrophotometer. All the samples contained $5 \%$ TCA and, following the recommendations of Logan, Mannell \& Rossiter (1952), these were heated for $15 \mathrm{~min}$, at $90^{\circ}$ (where this had not already been done in preparing the extract). The samples were suitably diluted and read at $268.5 \mathrm{~m} \mu$., where both nucleic acids have the same $\epsilon(\mathrm{P})$. The symbol $\epsilon(\mathrm{P})$ is used as defined by Chargaff \& Zamenhoff (1948). TCA blanks were heated and diluted in exactly the same way as the analytical solutions.

Pentose estimation. This was carried out according to the Mejbaum method, as modified by Patterson \& Dackerman (1952). Purified mycobacterial PNA (kindly provided by Professor M. Stacey) was used to relate pentose to phosphorus.

Deoxypentose estimation. Deoxypentose was estimated by the Dische diphenylamine reaction as described by Patterson \& Dackerman (1952), except that the colour was developed for $24 \mathrm{hr}$. at $37^{\circ}$. Purified mycobacterial DNA (Professor M. Stacey) was used as standard.

\section{EXPERIMENTAL}

The extraction of the phosphorus compounds of Mycobacterium smegmatis

Acetone extraction. Cold acetone extracted no more than $1 \%$ of the total cell phosphorus, and did not cause any further change in the various phosphorus fractions except to speed the subsequent extraction of the acid-soluble compounds. This was true even when the bacteria were stored under acetone for over a week. Acetone treatment was consequently used to stop metabolism and to permit the storage of samples.

Extraction of acid-soluble phosphorus. Treatment with ice-cold $5 \%$ TCA for $6 \mathrm{hr}$. was sufficient to extract the acid-soluble phosphorus compounds. Further extraction with $5 \%$ TCA in the cold did result in a very slow extraction of more phosphorus compounds, but this was due to a slow solution of nucleic acid and 'insoluble' polyphosphate. The acid-soluble compounds were not subjected to any detailed fractionation. Substances shown to be present were inorganic orthophosphate, inorganic polyphosphate (the 'soluble' metaphosphate of Juni, Kamen, Spiegelman \& Wiame, 1947), and phosphorylated riboflavin derivatives. Inorganic polyphosphate constituted most of the acidlabile phosphate in these extracts. The riboflavin derivatives were also present in considerable quantity, and were responsible for most of the ultraviolet absorption of the extracts.

Extraction of phospholipid. Anderson and others (e.g. Lederer, 1952) have shown that the phosphatides of mycobacteria are extracted by ethanol + ether. We found that about $65 \%$ of the phosphorus that could be extracted in this 
manner was removed by ethanol at room temperature, and about $30 \%$ by a subsequent extraction with ethanol +ether at $60^{\circ}$ for $4 \mathrm{~min}$. This was usually considered adequate, but a further extraction with ethanol + ether removed practically all remaining. Meissner \& Diller (1953), Sternberg \& Podoski (1953) and Mitchell \& Moyle (1954) used more elaborate extraction methods, but in view of the above considerations this does not seem necessary. The Reichert (1944) method, which was employed in modified form by Mitchell \& Moyle (1954), extracted about the same amount of phospholipid as the above method. The Reichert method involves heating to $90^{\circ}$, however, and this affected the other phosphorus fractions (see the section on the Schmidt-Thannhauser method). When the Reichert method was modified by finishing the removal of methanol at room temperature in vacuo, it gave a considerably smaller extraction of phospholipid than before.

Residual phosphorus. The method of Schneider (1945) was applied to the residues. This method consists in extracting the nucleic acids with hot TCA and differential estimation of the nucleic acids by determination of ribose and deoxyribose. When this was carried out on Mycobacterium smegmatis the results shown in Table 1 were obtained. There was a considerable excess of pentose and phosphorus, and a smaller excess of substance estimated as deoxypentose, over the nucleic acid present as measured by ultraviolet absorption.

Table 1. Comparison of content of phosphorus, pentose, deoxypentose, and nucleic acid in extracts prepared by treating Mycobacterium smegmatis (previously extracted with cold TCA, ethanol, and ethanol \pm ether) with $5 \%$ TCA at $90^{\circ}$ for $15 \mathrm{~min}$.

\begin{tabular}{|lc}
\multicolumn{1}{c}{ Constituents of extract } & $\mu \mathrm{g} . \mathrm{P} / \mathrm{mg}$. cell N \\
Total P & $\mathbf{1 7 3}$ \\
Apparent DNA-P (Dische) & $\mathbf{6 1}$ \\
Apparent PNA-P (Mejbaum) & $\mathbf{5 3 6}$ \\
Nucleic acid P (ultraviolet absorption) & $\mathbf{6 0}$
\end{tabular}

In order to study the excess phosphorus in purer form several attempts were made to extract it separately from the nucleic acids: (1) The cell residues were extracted with $0 \cdot 01 \mathrm{M}$-bicarbonate buffer, $\mathrm{pH} 9 \cdot 0$, at $19^{\circ}$ for successive periods up to a total of $24 \mathrm{hr}$. Nucleic acid and excess phosphorus were, however, extracted at a similar rate. (2) The residues were extracted with saturated aqueous urea at $37^{\circ}$ for $24 \mathrm{hr}$., and then several times with $\mathrm{M}-\mathrm{NaCl}$ at $19^{\circ}$. Again little separation of nucleic acid and excess phosphorus was obtained. (3) The residues were subjected to prolonged extraction with $5 \%$ TCA at $19^{\circ}$. The results of such an extraction are shown in Table 2. Most of the nucleic acid was extracted during the first $24 \mathrm{hr}$, and during the remaining periods the excess phosphorus was obtained with a greatly reduced nucleic acid contamination. These extracts were useful in studying the excess phosphorus with a minimum of interference from nucleic acid.

Studies made on the above extracts showed that most of the excess phosphorus was present as inorganic polyphosphate (metaphosphate). This was 
completely precipitated by barium at $\mathrm{pH} 4.5$ (except for a small amount hydrolysed to orthophosphate in the case of TCA extraction), and was entirely hydrolysed to orthophosphate in $7 \mathrm{~min}$. by $\mathrm{N}-\mathrm{HCl}$ at $100^{\circ}$. It gave a metachromatic reaction with toluidine blue (Wiame, 1949). Paper chromatography (Crowther, 1954) suggested that a mixture of high molecular weight polyphosphates was present in the extracts. The acid-lability of this polyphosphate provided a ready means of estimating it, provided that the nucleic acid content of the solutions concerned was known so that its hydrolysis might be allowed for as described earlier.

Table 2. Trichloroacetic acid extraction of Mycobacterium smegmatis cell residues (containing $\mathbf{3} \cdot 20 \mathrm{mg}$. nitrogen), previously extracted with cold TCA, ethanol and ethanol +ether

\begin{tabular}{|c|c|c|c|c|c|}
\hline 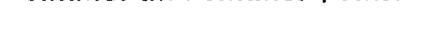 & & & Apparent & & \\
\hline Successive extractions with & $\begin{array}{c}\text { Acid- } \\
\text { labile } \\
\mathbf{P} \\
(\mu \mathrm{g} .)\end{array}$ & $\begin{array}{c}\text { Apparent } \\
\text { nucleic } \\
\text { acid P* } \\
(\mu \mathrm{g} .)\end{array}$ & $\begin{array}{c}\text { RNA-P } \\
\text { (Mej- } \\
\text { baum) } \\
(\mu \mathrm{g} .)\end{array}$ & $\begin{array}{c}\text { Apparent } \\
\text { DNA-P } \\
\text { (Dische) } \\
(\mu \mathrm{g} .)\end{array}$ & $\frac{E_{280}}{E_{268 \cdot 5}}$ \\
\hline $5 \mathrm{ml} .5 \%$ TCA at $1 \theta^{\circ}$ for $24 \mathrm{hr}$. & 194 & 135 & 142 & $3 \cdot 1$ & 1.07 \\
\hline $5 \mathrm{ml} .5 \%$ TCA at $19^{\circ}$ for $24 \mathrm{hr}$. & 215 & $\mathbf{3 9} \cdot \mathbf{9}$ & $58 \cdot 0$ & $1 \cdot 2$ & 1.00 \\
\hline $5 \mathrm{ml} .5 \%$ TCA at $19^{\circ}$ for $24 \mathrm{hr}$. & 140 & $10 \cdot 9$ & $40 \cdot 0$ & $\mathbf{2 \cdot 6}$ & $1 \cdot 01$ \\
\hline $5 \mathrm{ml} .5 \%$ TCA at $90^{\circ}$ for $15 \mathrm{~min}$. & 102 & $38 \cdot 1$ & 588 & 110 & $\mathbf{0 \cdot 7 6}$ \\
\hline
\end{tabular}

* The apparent nucleic acid $P$ was calculated directly from the ultraviolet absorption without making allowance for extraction of DNA purines.

In order to determine pentosenucleic acid (PNA) and deoxypentose nucleic acid (DNA) use was made of the fact that the two are extracted at different rates by an acid extraction more vigorous than that used to take out the acidsoluble compounds. Ogur \& Rosen (1950) used normal perchloric acid at $4^{\circ}$ for $18 \mathrm{hr}$. This temperature of extraction was inconvenient with the facilities available to us and so $5 \%$ TCA was used as a milder agent, so that a temperature of $19^{\circ}$ could be tried. The results of such an extraction are shown in Table 2. Obviously the Dische and Mejbaum methods are unsuitable for determining PNA and DNA in these extracts, especially in the final extract prepared at $90^{\circ}$, though the results with the Dische method do show that DNA is extracted to a very slight extent only by TCA at $19^{\circ}$ for $72 \mathrm{hr}$. To obtain more conclusive results use had to be made of ultraviolet absorption studies.

On extraction of purified DNA (kindly provided by Professor M. Stacey) from Mycobacterium phlei with $5 \%$ TCA for $72 \mathrm{hr}$. at $19^{\circ}$ it was found that the deoxypentose and phosphorus went into solution to a very slight extent only, but the purines were removed so that the residue was apurinic acid. When this residue was dissolved by heating with $5 \% \mathrm{TCA}$ at $90^{\circ}$ for $15 \mathrm{~min}$., it had an absorption maximum about $275 \mathrm{~m} \mu$., and the ratio of the extinction at $260 \mathrm{~m} \mu$. to that at $268.5 \mathrm{~m} \mu$. $\left(E_{280} / E_{288.5}\right)$ was 0.77 . When purified PNA was heated in $5 \% \mathrm{TCA}$ at $90^{\circ}$ for $15 \mathrm{~min}$. it gave an $\boldsymbol{E}_{260} / \boldsymbol{E}_{2885}$ of 1.05 . When the $E_{280} / E_{288.5}$ figures in Table 2 are examined it may be seen that the value for the residual material in $M$. smegmatis after extraction at $19^{\circ}$ for $72 \mathrm{hr}$, corresponded 
to that for apurinic acid, showing that the PNA had been removed quantitatively by the previous extractions and the DNA left as apurinic acid. Thus the DNA phosphorus in $M$. smegmatis can be estimated from the absorption at $268.5 \mathrm{~m} \mu$. of the heated extract from this residual material, using an $\epsilon(\mathbf{P})$ of 5700 (derived from apurinic acid prepared from purified DNA as described above). The PNA phosphorus in $M$. smegmatis can be estimated from the sum of the absorptions of the $19^{\circ}$ extracts at $268.5 \mathrm{~m} \mu$., using an $\epsilon(\mathrm{P})$ of 9800 , quoted by Logan et al. (1952) and confirmed for mycobacterial PNA (kindly provided by Professor M. Stacey), but allowance must be made for the absorption of the purines from the DNA. From the data quoted, this can be done by subtracting $\mathbf{4 2} \%$ of the calculated total DNA phosphorus.

It was found that this modified Ogur \& Rosen method for determining PNA and DNA could also be applied to Mycobacterium tuberculosis and $\boldsymbol{M}$. phlei, though some samples of these two organisms required a slightly longer extraction at $19^{\circ}$ for the complete removal of PNA. The $\boldsymbol{E}_{260} / \boldsymbol{E}_{268.5}$ ratio was always determined by extracts ' $R 2$ ' and ' $D$ ' (Fig. 1) to ensure that the separation was satisfactory. If either ratio deviated slightly, the amount of contamination by the other nucleic acid could be calculated from the deviation.

There appeared to be some phosphate in these extracts which was not accounted for as nucleic acid or acid-labile phosphate (the excess 'insoluble' phosphate of Tables 3-6). This was not due to the incomplete hydrolysis of the polyphosphate in $7 \mathrm{~min}$.- further hydrolysis (up to $15 \mathrm{~min}$.) did not liberate it as orthophosphate, nor did its amount vary proportionately to the amount of polyphosphate present. It may be present in the extracts as glycerophosphoric acid (Mitchell \& Moyle, 1951).

The phosphorus left in the residues after these extractions was assumed to be 'phosphoprotein' (Schneider, 1945). While in preliminary studies no nucleic acid or polyphosphate remained in the residues, it has since been found that on occasion (especially when larger samples were used) some DNA and a smaller amount of polyphosphate remained. A further extraction with $5 \%$ TCA at $90^{\circ}$ is therefore necessary to ensure the complete removal of these. As this was not usually done, some of the 'phosphoprotein' figures given later may be high (e.g. the higher figures in Table 6), and should therefore be taken to represent no more than an upper figure.

As a result of these studies on Mycobacterium smegmatis the scheme of extraction shown in the flow-sheet (Fig. 1) was adopted to obtain the results given later in this paper.

A study of the Schmidt-Thannhauser method. Since the Schmidt-Thannhauser method (1945) has been widely used for determining nucleic acid in bacteria, an attempt was made early in this work to apply it to mycobacteria. Diffculties due to their high lipid content and low recoveries of DNA caused it to be abandoned. From a recent re-investigation, however, it appears that it can be applied with some modification (Fig. 2).

Owing to the considerable amount of combined lipids in mycobacteria, extracted only by such drastic methods as ethanol + ether $+\mathrm{HCl}$ (see Lederer, 1952), it was impracticable to remove lipids completely. The subsequent 
behaviour of the material in the Schmidt-Thannhauser method was the same whether the lipid extraction was carried out with ethanol-ether at $60^{\circ}$ until no further lipid was extracted, or whether the Reichert method (1944) was used

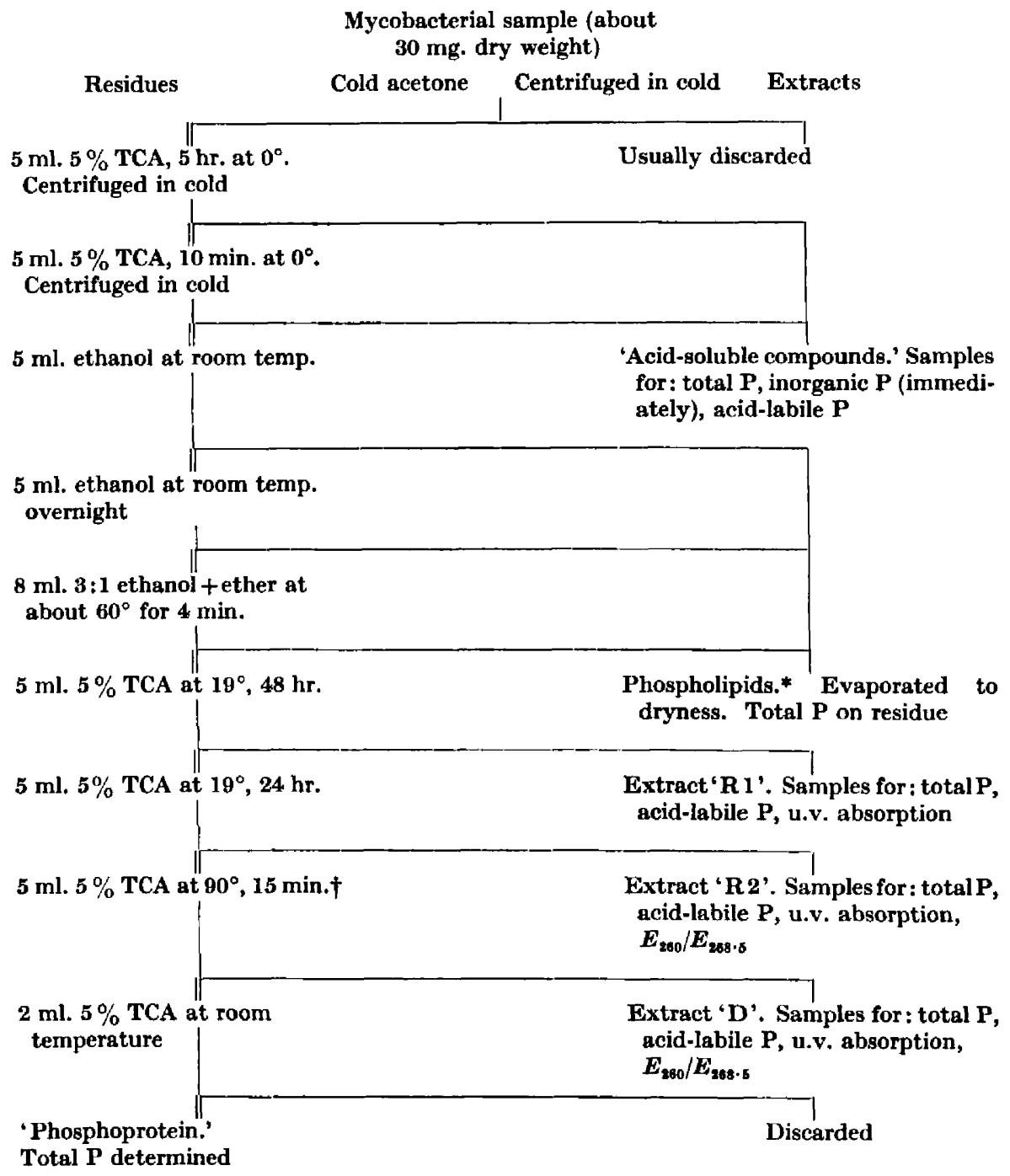

* For complete extraction of phospholipids a further ethanol-ether extraction at $60^{\circ}$ should be given.

$\dagger$ To ensure complete removal of DNA a further extraction with TCA at $90^{\circ}$ should be given.

Fig. 1. Flow-sheet describing extraction of phosphorus compounds from mycobacteria.

without heating to $90^{\circ}$, the removal of methanol being completed in vacuo at room temperature. The alkaline hydrolysis liberated a considerable amount of lipid, which had then to be removed by a number of extractions with warm ether. On centrifuging the suspension remaining, a substantial residue 
(R, Fig. 2) and a slightly cloudy supernatant were obtained. Acidification of the supernatant gave a heavy precipitate, leaving the PNA and polyphosphate in solution. The PNA, as determined from the ultraviolet absorption of the supernatant, was in fair agreement with the figure obtained by the TCA extraction method. The discrepancy was in part due to the persistent slight

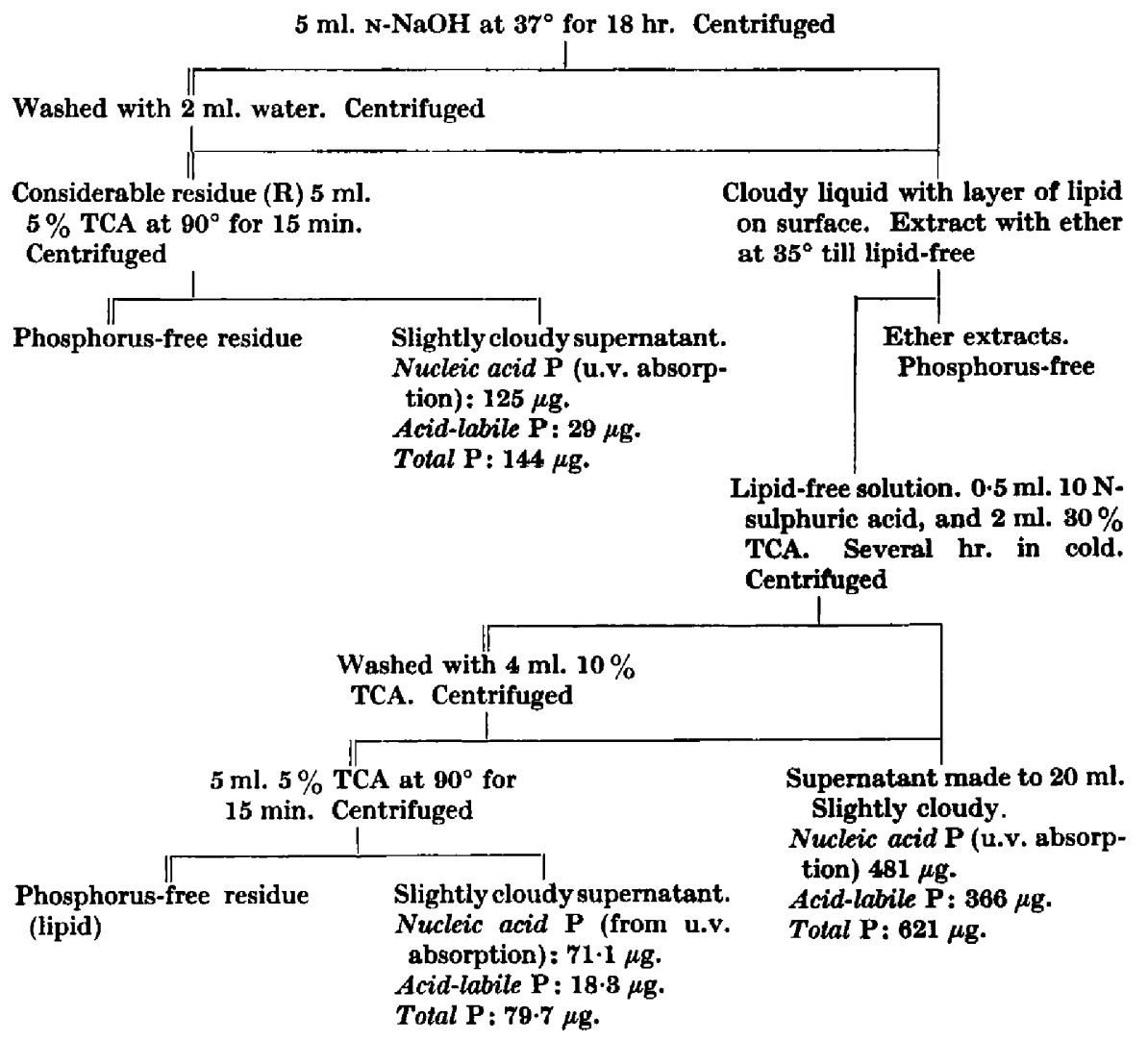

Vertical single lines indicate supernatants; vertical double lines indicate residues. Acidlabile phosphorus figures not corrected for nucleic acid hydrolysis.

Fig. 2. Application of the Schmidt-Thannhauser method to Mycobacterium smegmatis. $M$. smegmatis previously extracted with acetone and cold TCA; lipids then extracted after the Reichert method (1944). The material contained $400 \mu \mathrm{g}$. PNA-P and $227 \mu \mathrm{g}$. DNA-P by the method in Fig. 1.

cloudiness of this supernatant. The DNA was extracted from the precipitate with hot TCA, leaving a phosphorus-free waxy residue which, however, contained a considerable amount of ultraviolet-absorbing substances soluble in alkali-for this reason alkali was not used to dissolve the DNA. The absorption curve of the TCA solution showed that DNA only was present. It was accompanied by a little polyphosphate. The solution was again persistently slightly cloudy, so that a slight overestimation of the DNA was probable. The DNA was nevertheless much too low. Extraction of the first residue (R) with hot 
TCA brought a considerable amount of nucleic acid into solution, together with a little polyphosphate. The absorption curve of this nucleic acid showed it to be DNA, and it was present in sufficient quantity to account for practically all the missing DNA. Thus the results of this method are in rough agreement with those from the acid extraction method, and suggest that with a little further investigation the Schmidt-Thannhauser method would give reliable results for mycobacteria.

When the Reichert method was employed in unmodified form (the removal of methanol being completed at $70-90^{\circ}$ ), some of the troubles due to cloudy solutions were avoided, and the residue from the alkaline extraction was nucleic acid-free. However, the heat treatment appeared to cause degradation of the DNA, so that most of it failed to precipitate on acidification but remained in solution with the PNA.

Similar results were obtained with Mycobacterium phlei.

\section{Results of determinations of phosphorus compounds in several strains of mycobacteria}

A number of different samples of $\boldsymbol{M y c o b a c t e r i u m ~ s m e g m a t i s ~ w e r e ~ a n a l y s e d ~ b y ~}$ the methods which have been described, and some of the results are given in Table 3. The most striking feature of these results is their variability. The composition varies with age, as will be discussed later (Table 4), but variations observed were greater than could be explained on this basis. In fact, for all the determinations given in Table 4, material at approximately the same stage of growth was used-namely just before its multiplication rate had begun to diminish.

Observations revealed two extreme types of growth. The more usual (which we refer to as 'brittle' growth) gave a thin white film on the surface after 2 days. This thickened progressively to give a firm brittle mass which became at first faintly yellow ( 3 days), then a faint yellow-pink (4 days), after which it changed progressively towards light orange-brown. Rapid growth usually ended after 4 days. The medium developed only a slight yellow colour at this stage. Microscopic observation revealed rods about 4 times as long as broad, strongly acid-fast. The less usual 'leathery' growth developed in much the same way until the surface of the medium was covered. Subsequently, however, the film thickened only slightly, then took on a leathery consistency and began to sink, after which all growth stopped. The film of cells did not show any tendency to become pink, though it sometimes became yellow, and the medium became strongly yellow (the yellow colour in both cases being due to riboflavin or its derivatives, as shown by its ultraviolet absorption and fluorescence). Under the microscope the cells appeared much longer-many almost whip-like-and were less strongly acid-fast. 'Leathery' growth had characteristically much less DNA (calculated on a nitrogen basis) than 'brittle' growth.

The factors which cause the appearance of leathery growth are obscure. For long periods nothing but brittle growth was obtained, and then suddenly all the cultures would start to produce leathery growth. Sometimes a return to the parent cultures on agar produced a reversion to brittle growth, but most 
frequently this failed. Originally, P \& B without added ferric chloride was used for growing this organism, and it was found that the addition of about $10 \mu \mathrm{g} . / \mathrm{ml}$. ferric chloride resulted in brittle growth appearing again. This addition was consequently made to the routine media. Since then, however,

Table 3. Phosphorus-containing fractions of a number of cultures of Mycobacterium smegmatis grown on modified $P \& B$

\begin{tabular}{|c|c|c|c|c|c|c|c|}
\hline \multirow{2}{*}{$\begin{array}{l}\text { Type of growth } \\
\text { Age of culture (days) }\end{array}$} & \multicolumn{3}{|c|}{ Leathery } & \multicolumn{4}{|c|}{ Brittle } \\
\hline & 3 & 4 & 5 & 4 & $4^{*}$ & $5^{*}$ & $5^{*}$ \\
\hline & \multicolumn{7}{|c|}{$\mu \mathrm{g} . \mathbf{P} / \mathrm{mg}$. cell $\mathbf{N}$} \\
\hline Lipid P & $16 \cdot 1$ & $10 \cdot 7$ & $11 \cdot 9$ & - & $9 \cdot 1$ & $14 \cdot 1$ & $15 \cdot 0$ \\
\hline 'Phosphoprotein' P & $6 \cdot 1$ & $7 \cdot 7$ & $5 \cdot 3$ & - & - & - & - \\
\hline \multicolumn{8}{|l|}{ Acid-soluble $\mathbf{P}$} \\
\hline (i) Orthophosphate & $11 \cdot 4$ & $22 \cdot 7$ & & & - & $22 \cdot 8$ & $13 \cdot 0$ \\
\hline (ii) Acid-labile & - & - & $49 \cdot 8$ & $3 \theta \cdot 8$ & $8 \cdot 9$ & $5 \cdot 9$ & $5 \cdot 7$ \\
\hline (iii) Stable & - & - & & $\mathbf{2 4} \cdot \mathbf{3}$ & $39 \cdot 4$ & $30 \cdot 4$ & $19 \cdot 5$ \\
\hline PNA-P & $57 \cdot 5$ & $54 \cdot 3$ & $38 \cdot 5$ & $48 \cdot 4$ & $60 \cdot 9$ & $49 \cdot 2$ & $53 \cdot 8$ \\
\hline DNA-P & $12 \cdot 1$ & $17 \cdot 9$ & $18 \cdot 2$ & $39 \cdot 3$ & 38.7 & $59 \cdot 1$ & $56 \cdot 8$ \\
\hline 'Insoluble' polyphosphate & 110 & 118 & 131 & 128 & 168 & 143 & 125 \\
\hline Excess 'insoluble' $\mathbf{P}$ & - & - & 8.0 & $16 \cdot 0$ & $\mathbf{2 8 \cdot 3}$ & - & - \\
\hline
\end{tabular}

* The figures for these three cultures are calculated in terms of protein nitrogen, not total nitrogen. The ratio protein nitrogen/total nitrogen was usually about $0 \cdot 83$.

Table 4. Effect of age of culture on the phosphorus-containing fractions of Mycobacterium smegmatis

\begin{tabular}{|c|c|c|c|c|c|c|c|c|}
\hline \multirow{2}{*}{$\begin{array}{l}\text { Type of growth } \\
\text { Age of culture (days) }\end{array}$} & \multicolumn{5}{|c|}{ Intermediate } & \multicolumn{3}{|c|}{ Brittle } \\
\hline & 2 & 3 & $3 \cdot 5$ & 4 & $\mathbf{5}$ & 4 & 5 & 7 \\
\hline & \multicolumn{8}{|c|}{$\mu \mathrm{g} . \mathbf{P} / \mathbf{m g} \cdot$ cell $\mathbf{N}$} \\
\hline Lipid P & $9 \cdot 8$ & $12 \cdot 8$ & $13 \cdot 2$ & $14 \cdot 6$ & $12 \cdot 1$ & $13 \cdot 3$ & $12 \cdot 0$ & $9 \cdot 6$ \\
\hline $\begin{array}{l}\text { 'Phosphoprotein' P } \\
\text { Acid-soluble P }\end{array}$ & $12 \cdot 5$ & $10 \cdot 6$ & $9 \cdot 5$ & $10 \cdot 2$ & $11 \cdot 5$ & $11 \cdot 9$ & $11 \cdot 8$ & 14.9 \\
\hline $\begin{array}{l}\text { (i) Orthophos } \\
\text { phate }\end{array}$ & $7 \cdot 8$ & $8 \cdot 8$ & 一 & $8 \cdot 2$ & $9 \cdot 0$ & $8 \cdot 6$ & $8 \cdot 6$ & $19 \cdot 4$ \\
\hline (ii) Acid-labile & $4 \cdot 8$ & $4 \cdot 9$ & - & $\mathbf{5} \cdot \mathbf{5}$ & $5 \cdot 6$ & $5 \cdot 4$ & $5 \cdot 4$ & $7 \cdot 0$ \\
\hline (iii) Stable & $8 \cdot 4$ & $20 \cdot 0$ & $\ldots$ & $20 \cdot 5$ & $18 \cdot 1$ & $13 \cdot 1$ & $11 \cdot 2$ & $10 \cdot 9$ \\
\hline PNA-P & $52 \cdot 5$ & $54 \cdot 2$ & $49 \cdot 1$ & $39 \cdot 4$ & $\mathbf{3 7} \cdot \mathbf{3}$ & $33 \cdot 5$ & $\mathbf{3 2 \cdot 5}$ & $32 \cdot 6$ \\
\hline DNA-P & c. 50 & $29 \cdot 9$ & $23 \cdot 8$ & $23 \cdot 6$ & $22 \cdot 2$ & $51 \cdot 5$ & $52 \cdot 7$ & $54 \cdot 3$ \\
\hline $\begin{array}{l}\text { 'Insoluble' } \\
\text { polyphosphate }\end{array}$ & $20 \cdot 2$ & $53 \cdot 0$ & $84 \cdot 0$ & $140 \cdot 3$ & $153 \cdot 0$ & $73 \cdot 4$ & $76 \cdot 0$ & $70 \cdot 0$ \\
\hline $\begin{array}{l}\text { Excess 'insoluble' } \\
\text { phosphate }\end{array}$ & $\ldots$ & $11 \cdot 6$ & - & $10 \cdot 5$ & $8 \cdot 7$ & $19 \cdot 7$ & $19 \cdot 5$ & $21 \cdot 5$ \\
\hline
\end{tabular}

Both cultures were derived from the same inoculum and grown under identical conditions on modified $\mathbf{P} \& \mathbf{B}$.

leathery growth has appeared in media modified in this way, and at present best growth is obtained when ferric chloride is omitted. On occasion, leathery growth has been obtained on fresh $\mathbf{P} \& \mathbf{B}$, and brittle growth when the batch of medium used was a couple of months old, but again this was not always true. Bacterial contamination is not responsible, nor does there seem to be any question of bacteriophage being involved. 
Table 4 shows the effect of age on two cultures of Mycobacterium smegmatis derived from the same inoculum. One of these cultures developed an intermediate type of growth, the other brittle growth. Growth in the intermediate culture began to slow down after the second day, the DNA dropped to a low level, the PNA dropped more slowly, and the polyphosphate rose rapidly. In the brittle culture a rapid rate of growth continued even up to 7 days, and it may be seen that the DNA remained at a high level, while the polyphosphate rose to a less high level than in the other culture and remained there for the duration of the experiment. Otherwise the two cultures showed a similar composition, and changed only slightly over the period studied.

Table 5. Phosphorus-containing fractions of Mycobacterium phlei

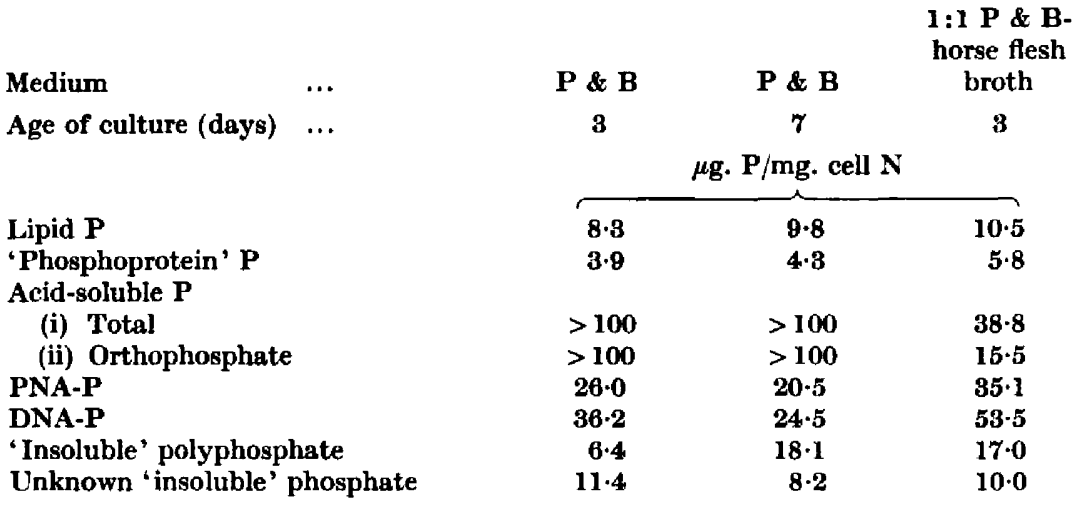

Mycobacterium phlei was not as erratic in its growth on $\mathbf{P} \& \mathbf{B}$ type media as M. smegmatis. Some figures for the phosphorus compounds of $\boldsymbol{M}$. phlei are given in Table 5. Noteworthy was the low PNA/DNA ratio-this was invariably less than 1 , whilc in $M$. smegmatis it varied from $0 \cdot 6$ to nearly 5 . The polyphosphate in $M$. phlei was usually very low, and never reached the levels found in $\boldsymbol{M}$. smegmatis. The high level of orthophosphate found in most cultures of $\boldsymbol{M}$. phlei grown on $\mathrm{P} \& \mathrm{~B}$ is due to precipitation of magnesium ammonium phosphate from the medium. The medium as prepared is almost saturated with magnesium phosphate, and the increased alkalinity and liberation of ammonia during growth cause this precipitation. Crystals of magnesium ammonium phosphate may usually be seen attached to the underside of the pellicle. The same effect has been observed on occasion with $M$. smegmatis and $M$. tuberculosis so that in these cases, too, the orthophosphate may be overestimated. The magnesium ammonium phosphate is not removed during washing, but dissolves during the extraction of acid-soluble compounds.

Results for analyses of Mycobacterium tuberculosis are given in Table 6. This includes several strains of several ages, yet a fair degree of constancy of composition may be seen. Phospholipid was usually rather higher than in M. smegmatis. PNA was lower than in $\boldsymbol{M}$. smegmatis, agreeing more with the level in M. phlei. The PNA/DNA ratio was 1.5 to 2 . 


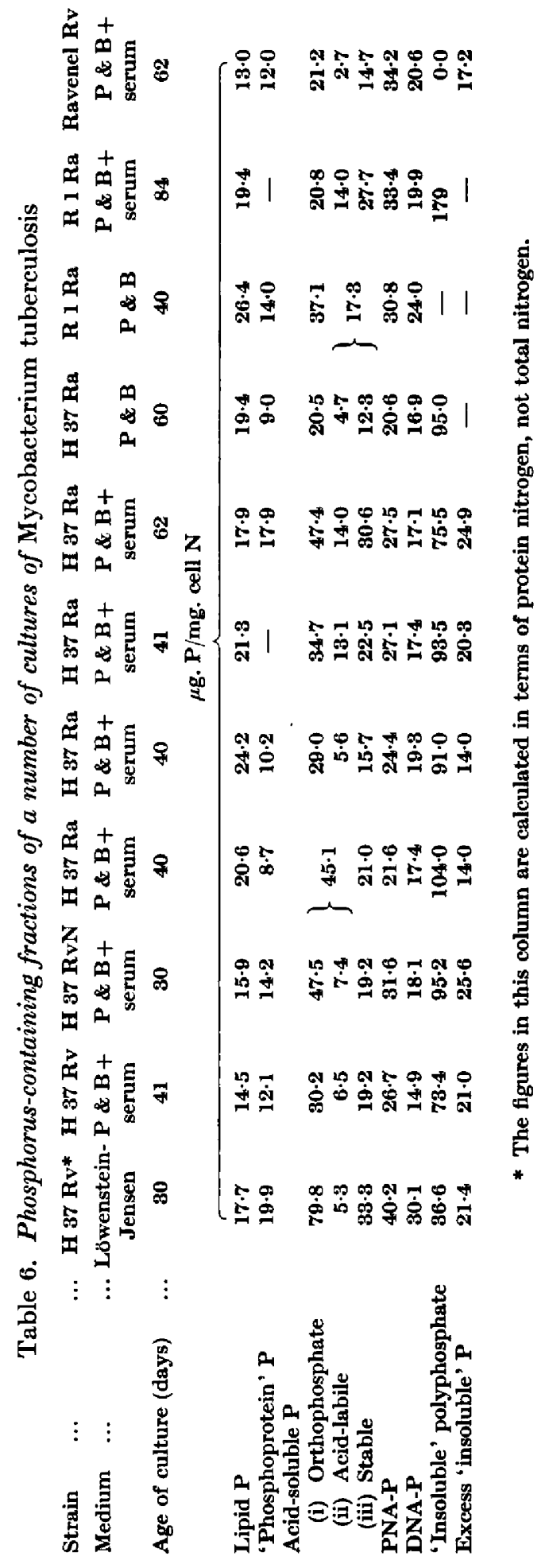


During this research it was desired to study the changes which took place immediately after the transfer of actively growing material to a fresh culture medium. As will be seen by referring to the Methods section, the new medium had not exactly the same composition as the growth medium. Since it was made up at three times strength, magnesium was omitted to avoid phosphate precipitation on autoclaving. Consequently only traces of magnesium were present. It had a higher sodium content than the growth medium and also, as there was some magnesium phosphate precipitation in the latter medium, a slightly higher phosphate content. Further, to make the manipulation of these rather hydrophobic organisms easier, the medium was made to contain a final concentration of $0.07 \%$ Tween 80 . Previous experimentation had shown, however, that these changes did not make any difference to the behaviour of the culture during the period studied.

Table 7. Changes relative to nitrogen in the phosphorus-containing fractions of Mycobacterium smegmatis after transfer of a 5-day old culture on modified $P \& B$ into fresh $P \& B$

Time after inoculation (hr.) $\ldots$

$$
\text { o }
$$

3

6

$11 \cdot 5$

mg. N/10 ml. medium

Total cell nitrogen

Lipid $\mathbf{P}$

'Phosphoprotein' P

Acid-soluble $\mathbf{P}$

(i) Orthophosphate + acid-labile

(ii) Stable

PNA.P

DNA-P

'Insoluble' polyphosphate

\begin{tabular}{|c|c|c|c|}
\hline \multicolumn{4}{|c|}{$\mathrm{mg} . \mathrm{N} / 10 \mathrm{ml}$. medium } \\
\hline $2 \cdot 05$ & $\mathbf{2 \cdot 3 8}$ & $\mathbf{2 \cdot 8 6}$ & 3.82 \\
\hline \multicolumn{4}{|c|}{$\mu \mathrm{g} . \mathrm{P} / \mathrm{mg}$. cell $\mathrm{N}$} \\
\hline $14 \cdot 1$ & $13 \cdot 1$ & $11 \cdot 5$ & $10 \cdot 4$ \\
\hline $5 \cdot 1$ & $5 \cdot 1$ & $5 \cdot 2$ & $5 \cdot 3$ \\
\hline 28.0 & 41.7 & $41 \cdot 9$ & $50 \cdot 8$ \\
\hline 14.9 & $14 \cdot 7$ & $17 \cdot 9$ & $15 \cdot 2$ \\
\hline $49 \cdot 1$ & $46 \cdot 1$ & $48 \cdot 2$ & 46.7 \\
\hline $17 \cdot 8$ & $18 \cdot 0$ & $20 \cdot 4$ & $20 \cdot 8$ \\
\hline 138 & 115 & $81 \cdot 6$ & $62 \cdot 0$ \\
\hline
\end{tabular}

Table 7 shows the changes in such a culture of Mycobacterium smegmatis during the first $11 \mathrm{hr}$. The total nitrogen showed an increase within $3 \mathrm{hr}$., and had almost doubled in $11 \mathrm{hr}$. 'Phosphoprotein', PNA, and stable acid-soluble phosphate increased at about the same rate as nitrogen and DNA slightly faster. The changes in the PNA and DNA, however, varied according to their initial levels-when material with high DNA was used, DNA increased more slowly than nitrogen and PNA more rapidly. The sum of orthophosphate and acid-labile soluble phosphate increased at a greater rate than nitrogen, while phospholipid increased at a slower rate. A most striking effect was the actual decrease in insoluble polyphosphate.

When similar experiments were done using 40-day-old cultures of $\mathbf{M y c o -}$ bacterium tuberculosis $\mathrm{H3} 7 \mathrm{Ra}$ the changes were very much slower. Nitrogen increased by a factor of about 1.2 in $22 \mathrm{hr}$. The picture was much the same as in $M$. smegmatis, but in neither of the two experiments did polyphosphate show a decrease and in one it increased relative to nitrogen over a period of $24 \mathrm{hr}$. In one of the experiments a very striking drop in orthophosphate was 
observed. This was probably due, however, to magnesium ammonium phosphate having been introduced with the inoculum (see earlier) and then slowly dissolving.

\section{DISCUSSION}

Table 8 gives analytical results gathered from the literature for some strains of mycobacteria. For comparison the range of our results is shown, calculated on the same basis (dry weight). This recalculation of our values is only approximate in the case of Mycobacterium tuberculosis and $\boldsymbol{M}$. phlei. Only in the case of $\boldsymbol{M}$. smegmatis was the dry weight of samples determined, and so the results for $M$. phlei and $\boldsymbol{M}$. tuberculosis were recalculated assuming $12 \mathrm{mg}$. dry weight/mg. nitrogen, which is the average value for $M$. smegmatis. It will be seen that the figures from the literature are rather too fragmentary to make possible a detailed comparison with the figures in this paper. They do, however, serve to confirm that the phosphorus-containing components vary according to the strain and the cultural conditions. Some of the results, however, appear to differ from the results quoted in this paper by an amount greater than could be explained on these grounds. For example, the figures for the acid-soluble phosphate of $M$. phlei given by Sternberg \& Podoski (1953) seem very high compared with the other figures in Table 8 . The nucleic acid figures given by Mitchell \& Moyle (1954) are very different from ours. This may be due to their having used the Schmidt-Thannhauser method without realizing its difficulties when applied to mycobacteria.

It would be interesting to know in what manner the DNA which resists extraction by the Schmidt-Thannhauser method is held. Juni, Kamen, Reiner \& Spiegelman (1948) have reported that the polyphosphate of yeast is likewise bound in the alkali-insoluble residues. In the mycobacteria studied only a trace of polyphosphate is held in this fashion.

The $\mathbf{P} \& \mathbf{B}$ modification which was used in this work has not proved to be ideal for the study of the phosphorus compounds of the organisms. It has a very high content of magnesium so that magnesium ammonium phosphate precipitates very readily, as $\mathrm{pH}$ value and ammonia content of the medium rise during growth. On the other hand, this medium gives a much higher yield of cells than any other which we have tried.

Attention should be called to the fact that the values for mycobacterial PNA and DNA quoted in a previous paper (Winder \& Denneny, 1954) were erroneous. It was not then realized that DNA purine was extracted with PNA by $5 \% \mathrm{TCA}$ at $19^{\circ}$, and that allowance must be made for this when calculating the nucleic acid values from the ultraviolet absorption figures.

During this work it was found that inorganic polyphosphate is a major phosphorus component of the strains studied (with the exception of the one culture of Ravenel $\mathbf{R v}$ investigated). The substance is a high molecular weight polymer of orthophosphate, and has been referred to as 'metaphosphate' by many writers on the subject, including the present authors. However, as metaphosphoric acid properly has the formula $\left(\mathrm{HPO}_{3}\right)_{n}$, the use of this term implies cyclical structure. As this has not been shown to be true of the material 


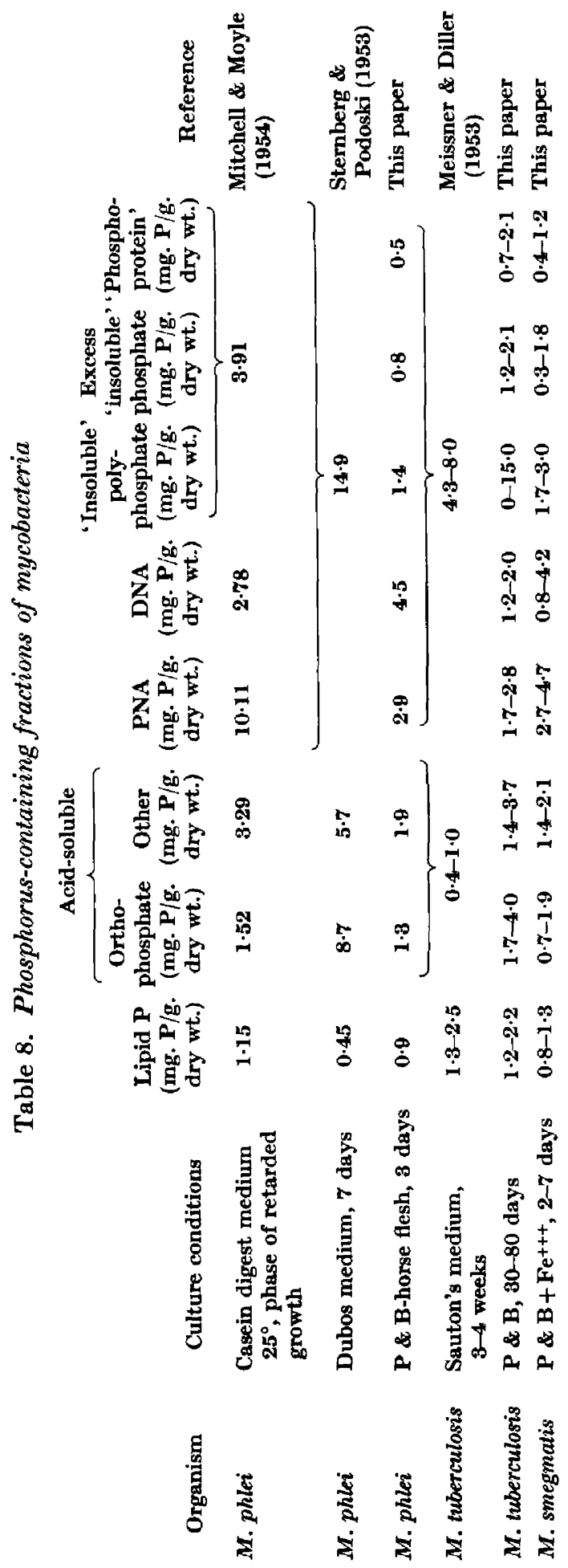




\section{Phosphorus compounds of mycobacteria}

in mycobacteria, and is very likely untrue, it is preferable to use the noncommittal term 'polyphosphate'. Inorganic polyphosphate has been recorded as being present in a considerable number of lower plants (see review by Schmidt, 1951). It has been found in mycobacteria (Ruska et al. 1952; Winder \& Denneny, 1954) and its significance in these organisms has been discussed (Winder \& Denneny, 1954).

It has usually been regarded as a storage form of phosphate, and perhaps energy, being used up during periods of active growth and accumulated during resting periods. Most of the results in this paper are in keeping with this, e.g. the increase in polyphosphate with the age of a culture whose growth is slowing down (Table 4), and the drop in polyphosphate on inoculation of $\mathrm{Myco}$ bacterium smegmatis into fresh medium (Table 7). The rise in polyphosphate found on inoculating $M$. tuberculosis into fresh medium does not appear to conform with this idea. However, it may be that in this organism the anabolic reactions utilizing polyphosphates have a longer lag period than the catabolic reactions leading to its formation so that, over the immediate post-inoculation period studied, polyphosphate storage conditions would still prevail.

In subsequent papers the function of polyphosphate in mycobacteria will be discussed in the light of results obtained under abnormal growth conditions, radioactive tracers and cell-free extracts, which have given further information on the question.

We wish to thank Dr Vincent C. Barry, the Director of these laboratories, for encouragement and stimulating discussion, and Messrs Arthur Guinness, Son and Co. (Ireland) Ltd., for generous financial assistance.

\section{REFERENCES}

American Trudeau Society (1950). Report of the Laboratory Sub-committee of the Committee on Medical Research and Therapy. Amer. Rev. Tuberc. 61, 274.

Barry, V. C., Conalty, M. L., Denneny, J. M., Gaffney, E. E. \& Winder, F. (1955). Studies on isoniazid-resistant strains of Mycobacterium tuberculosis. I. Growth requirements of strains resistant to 100 micrograms of isoniazid per milliliter. Amer. Rev. Tuberc. 71, 785.

BajaJ, V. \& Krishnan, P. S. (1953). Phosphate partition in trichloroacetic acid extracts of mold tissue. Arch. Biochem. Biophys. 47, 34.

Berenblum, I. \& Chain, E. (1938). An improved method for the colorimetric determination of phosphate. Biochem. J. 32, 295.

Chargaff, E. \& Saidel, H. (1949). On the nucleoproteins of the avian tubercle bacilli. J. biol. Chem. 177, 417 .

Chargaff, E. \& Zamenhof, S. (1948). The isolation of highly polymerised desoxypentosenucleic acid from yeast cells. J. biol. Chem. 173, $\mathbf{8 2 7}$.

Conway, E. J. (1950). Microdiffusion Analysis and Volumetric Error, 3rd ed. London: Crosby Lockwood.

Crowther, J. P. (1954). Filter paper chromatographic analysis of phosphate mixtures. Nature, Lond. 173, 486.

Ebel, J. P. (1952). Recherches sur les polyphosphates contenus dans diverses cellules vivantes. III. Recherche et dosage des polyphosphates dans les cellules des divers microorganismes et animaux supérieurs. Bull. Soc. Chim. biol., Paris, $34,491$. 
Hawes, R. C. \& Skavinski, E. R. (1942). Diffusion micro-method for nitrogen. Industr. Engng Chem. (Anal.), 14, 917.

Jun, E., Kamen, M. D., Spiegelman, S. \& Wiame, J. M. (1947). Physiological heterogeneity of metaphosphate in yeast. Nature, Lond. 160, 717.

Juni, E., Kamen, M. D., Reiner, J. M. \& Spiegelman, S. (1948). Turnover and distribution of phosphate compounds in yeast metabolism. Arch. Biochem. 18, 387.

Lederer, E. (1952). Chemistry and Biochemistry of Mycobacteria. Colloquium on the Chemotherapy of Tuberculosis, p. 1. Dublin: Parkside Press.

LePAGE, G. A. (1949). Methods for the analysis of phosphorylated intermediates. In Manometric Techniques and Tissue Metabolism, p. 185, ed. by W. W. Umbreit, R. H. Burris \& J. F. Stauffer, 2nd ed. Minneapolis: Burgess Publishing Co.

Logan, J. E., Mannell, W. A. \& Rossiter, R. J. (1952). Estimation of nucleic acids in tissue from the nervous system. Biochem. J. 51, 470.

MARSHAK, A. \& VOGEL, H. J. (1951). Microdetermination of purines and pyrimidines in biological material. J. biol. Chem. 189, 507 .

Meissner, J. \& Dillen, W. (1953). Uber die Aufnahme von Ortho- und Metaphosphat durch das Mycobacterium tuberculosis. Z. Hyg. InfektKr. 137, 518.

Meissner, J. \& KropP, F. (1953). Utber die Phosphatresorption beim Mycobacterium tuberculosis. Z. Hyg. InfektKr. 137, 429.

MrTchell, P. \& MoYLe, J. (1951). Isolation of hydrolytic products of a glycerophospho-compound from Micrococcus pyogenes. J. gen. Microbiol. 5, 966 .

Mrtchell, P. \& Moyle, J. (1954). The Gram reaction and cell composition: Nucleic acids and other phosphate fractions. J. gen. Microbiol. 10, 533.

OGUR, M. \& Rosen, G. (1950). The nucleic acids of plant tissues. I. The extraction and estimation of desoxypentose nucleic acid and pentose nucleic acid. Arch. Biochem. 25, 262.

Patterson, E. K. \& Dackerman, M. E. (1952). Nucleic acid content in relation to cell size in the mature larval salivary gland of Drosophila melanogaster. Arch. Biochem. Biophys. 36, 97.

Reichent, R. (1944). Quantitative Bestimmung des Gesamtlipoidgehaltes von Naturstoffen. Helv. chim. acta, 27, 861.

Ruska, H., Bringmann, G., Neckel, I. \& Schuster, G. (1952). Uber die Entwicklung sowie den morphologischen und zytochemischen Aufbau v. Mycobacterium avium (Chester). Z. wiss. Mikr. 60, 425.

Schmidt, G. \& Thannhauser, S. J. (1945). A method for the determination of deoxyribonucleic acid, ribonucleic acid and phosphoproteins in animal tissues. J. biol. Chem. 161, 83.

Scrmidt, G. (1951). The biochemistry of inorganic polyphosphates and metaphosphates. Phosphorus Metabolism, 1, p. 433, ed. by W. D. McElroy \& B. Glass. Baltimore: Johns Hopkins Press.

Schneider, W. C. (1945). Phosphorus compounds in animal tissues. I. Extraction and estimation of deoxypentose nucleic acid and pentose nucleic acid. $J$. biol. Chem. 161, 293.

Sternberg, J. \& Podoski, M. O. (1958). Recherches faites avec les mycobactéries marquées. I. Mycobacterium phlei et radiophosphore: technique d'obtention et vitesse d'utilisation du phosphore exogène. Ann. Inst. Pasteur, 84, 1.

Wiame, J. M. (1949). The occurrence and physiological behaviour of two metaphosphate fractions in yeast. $J$. biol. Chem. 178, 919.

Winder, F. \& DeNNENY, J. M. (1954). Metaphosphate in mycobacterial metabolism. Nature, Lond. 174, 858. 